\title{
Impacts of lon-Pairing Effects on Linear and Nonlinear Photophysical Properties of Polymethines Dyes
}

\author{
Simon Pascal, ${ }^{*[a, b]}$ San-Hui Chi, ${ }^{[c]}$ Joseph W. Perry, ${ }^{[c]}$ Chantal Andraud, ${ }^{*[a]}$ Olivier Maury ${ }^{*[a]}$ \\ [a] Laboratoire de Chimie, Univ. Lyon, ENS Lyon, CNRS, Université Lyon 1, 46 Allée d'ltalie, 69364 Lyon, France. E- \\ mail: chantal.andraud@ens-lyon.fr; olivier.maury@ens-lyon.fr \\ [b] Current adress: Aix Marseille Université, CNRS UMR 7325, CINaM, Campus de Luminy, case 913, 13288 Marseille \\ cedex 09, France. E-mail: pascal@cinam.univ-mrs.fr \\ [c] School of Chemistry and Biochemistry, Center for Organic Photonics and Electronics, Georgia Institute of \\ Technology, 901 Atlantic Drive NW, Atlanta, Georgia 30332-0400, United States
}

\begin{abstract}
The two-photon absorption (2PA) and photophysics of heptamethine dyes featuring cyanine or dipolar electronic structures has been compared for the first time. The perfectly delocalized cyanine system is classically characterized by a two-photon transition matching the vibronic component of its lower energy absorption band. The dipolar species is generated by ion-pairing with a hard counterion in nondissociating solvent and displays significant optical properties modifications, including dramatic hypochromic shift of absorption,
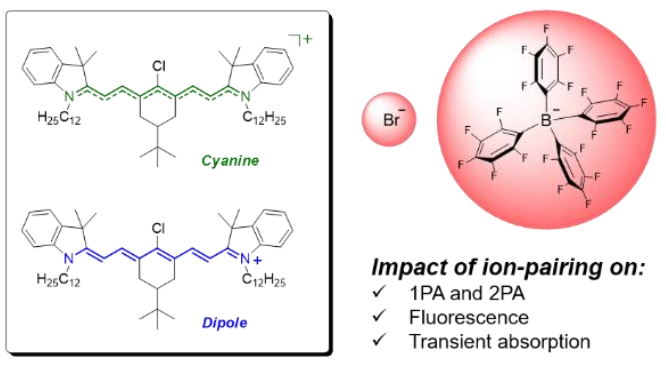

Impact of ion-pairing on: $\checkmark$ PA and 2PA $\checkmark$ Fluorescence weaker emission and 2PA matching the lower energy transition, thus revealing symmetry breaking within the polymethine electronic structure.
\end{abstract}

\section{Introduction}

Polymethines are a fascinating class of dyes in which a positive (or negative) charge is delocalized over the conjugated skeleton comprised of an odd number of $\mathrm{Csp}^{2}$ atoms between two electron donating (and/or withdrawing) moieties. In the most interested cyanine state (form I, Figure 1), sometimes also called ideal polymethine state, the charge is delocalized over the entire conjugated backbone with vanished bond-length alternation (BLA, i.e. the difference between two adjoining $\mathrm{Csp}^{2}-\mathrm{Csp}^{2}$ bonds) and results in the distinctive absorption spectrum that has been extensively studied over the last decades. As shown in Figure 1, the absorption spectrum features a sharp, intense absorption band with a characteristic high-energy shoulder. This strong absorption can be enhanced or redshifted into the near-infrared (NIR) spectral range, such as in heptamethine derivatives, by simple engineering of the extremities or elongation of the conjugated pathways. ${ }^{1-3}$ The cyanine emission exhibits a very small Stokes shift, signature of a minimal excited state molecular relaxation.

Within the cyanine family, pentamethines and heptamethines with five- and seven-carbon bridges, respectively, have attracted much attention for applications in bio-imaging and material science..$^{4-9}$ Commercially available indocyanine green, is largely

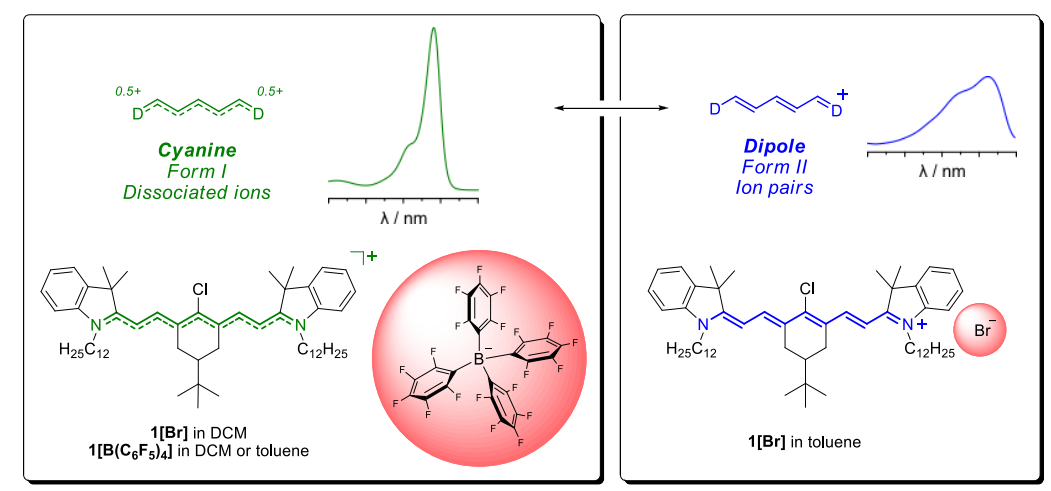

Figure 1. Representation of the cyanine and dipolar electronic structures of polymethine dyes with their corresponding absorption profiles, and illustration of the ion-pairing phenomenon within the heptamethine $\mathbf{1}$, depending on the counterion and solvent natures. ${ }^{10}$ 
used for in vivo bio-imaging applications or further bioconjugation. ${ }^{11,} 12$ Some polymethines have also been extensively studied for nonlinear optical applications, such as alloptical signal processing or optical limiting, in the telecommunication wavelengths range [1.3-1.5 $\mu \mathrm{m}] .{ }^{13-19}$ The development of such applications requires the optimization of the optical properties of the material through a precise molecularlevel manipulation of the electronic structure of the polymethine dyes, by controlling the nature of the counterion. ${ }^{16,20-22}$ In fact, it is well known that polymethines can present other ground state electronic structures, as the charge is localized at one extremity, breaking the symmetry of the conjugated backbone and forming a dipolar chromophore. ${ }^{23}$ This electronic state, also known as polyene-like state, features a broad absorption band (form II, Figure 1). This phenomenon, generally referred to as "crossing the cyanine limit" in the literature, can be achieved by (i) the lengthening of the conjugated skeleton, ${ }^{24-26}$ (ii) the modification of the donor end group, ${ }^{19,27}$ (iii) of solvent polarity ${ }^{28}$ or (iv) monitoring ion-pairing effects. ${ }^{10,29}$ Furthermore, the existence of a third ground state electronic structure called bis-dipole has also been described as the charge is localized on the central $\mathrm{Csp}^{2}$ atom of the bridge under the influence of vicinal electron donating moieties. ${ }^{30}$ In a general way, the transition from one state to another is monitored using absorption spectroscopy, which provides a strong indication of each electronic structure. Herein, we generalized this study and examined in detail the impact of the ground state electronic structure on other spectroscopic features like emission, nonlinear absorption and transient absorption spectroscopic properties.

In particular, the transition from cyanine to dipole electronic structures involves a drastic modification of the electronic density distribution over the conjugated bridge. Consequently, a significant impact on the molecular polarizability and hence on the nonlinear optical properties is anticipated, as theoretically predicted in the case of symmetry breaking by ion-pairing. ${ }^{20,31,32}$ For this purpose, we prepared the heptamethine 1 featuring lipophilic dodecyl substituents to ensure optimal solubility in classical organic solvents in association with small $\left(\mathrm{Br}^{-}\right)$or bulky $\left(\mathrm{B}\left(\mathrm{C}_{6} \mathrm{~F}_{5}\right)_{4}^{-}\right)$counterions (Figure 1). While the cyanine state is classically observed in chlorinated solvent with both counterions, the dipolar state is reached by ion-paring effect in nonpolar solvent (e.g. toluene) in the case of $\mathbf{1}[\mathbf{B r}]$. This fine control of the cyanine to dipole transition reveals the impact of the symmetry of the electronic distribution on a larger panel of photophysical properties.

\section{Results and Discussion}

The improved solubility of heptamethine 1 allows to study its photophysical properties in dichloromethane (DCM, dissociating solvent) but also in a non-dissociating apolar solvent like toluene with both counterions. As expected, in the case of the bulky $\left[\mathrm{B}\left(\mathrm{C}_{6} \mathrm{~F}_{5}\right)_{4}\right]$ counterion, no ion-pairing occurs in nonpolar solvent, thus the absorption and emission spectra of $\mathbf{1}\left[\mathbf{B}\left(\mathbf{C}_{6} \mathbf{F}_{5}\right)_{4}\right]$ are identical in both solvents with a small Stokes shift of ca. $200 \mathrm{~cm}^{-1}$ (Figure 2 and Table 1), as previously described. ${ }^{10}$ The absorption profile is typical of a polymethine in the cyanine state with a sharp and intense transition featuring a characteristic high-energy vibronic shoulder. The emission band is the perfect mirror of the absorption band with a significant quantum yield in both solvents
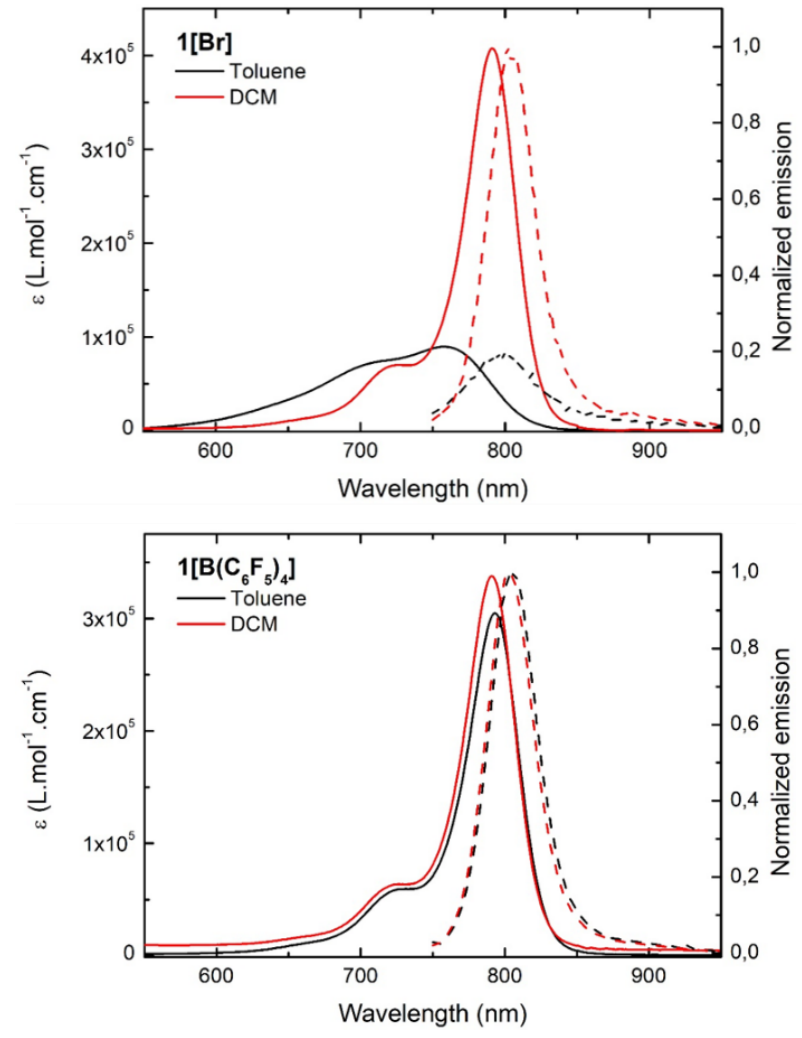

Figure 2. Absorption (plain line) and emission (dotted line) spectra of polymethines $\mathbf{1}[\mathbf{B r}]$ (top) and $\mathbf{1}\left[\mathbf{B}\left(\mathbf{C}_{6} \mathbf{F}_{5}\right)_{4}\right]$ (bottom) in toluene (black) and DCM (red).

Table 1. Optical and photo-induced kinetic properties of $\mathbf{1}[\mathrm{Br}]$ and $\mathbf{1}\left[\mathbf{B}\left(\mathrm{C}_{6} \mathrm{~F}_{5}\right)_{4}\right]$ in toluene and DCM.

\begin{tabular}{|c|c|c|c|c|}
\hline & \multicolumn{2}{|c|}{$1[\mathrm{Br}]$} & \multicolumn{2}{|c|}{$1\left[B\left(C_{6} F_{5}\right)_{4}\right]$} \\
\hline & toluene & DCM & toluene & DCM \\
\hline$\lambda_{1 \mathrm{PA}}{ }^{[\mathrm{al}]} / \mathrm{nm}$ & 758 & 791 & 793 & 791 \\
\hline $\begin{array}{c}\varepsilon / \\
\text { L.mol } \\
\left.\right|^{-1} \cdot \mathrm{cm}^{-1}\end{array}$ & 90000 & 408000 & 305000 & 338000 \\
\hline$\sigma_{01}{ }^{[a]} / \mathrm{cm}^{2}$ & $3.4 \times 10^{-16}$ & $1.6 \times 10^{-15}$ & $1.2 \times 10^{-15}$ & $1.3 \times 10^{-15}$ \\
\hline$\lambda_{\mathrm{em}}{ }^{[\mathrm{a}]} / \mathrm{nm}$ & 806 & 808 & 806 & 802 \\
\hline$\Phi$ & 0.04 & 0.29 & 0.24 & 0.29 \\
\hline$\tau / \mathrm{ns}$ & $<0.4$ & 1.3 & 1.2 & 1.3 \\
\hline$\lambda_{2 \mathrm{PA}}{ }^{[\mathrm{a}][\mathrm{b}]} / \mathrm{nm}$ & 700 & 723 & 720 & 726 \\
\hline$\delta^{[\mathrm{a}] \mathrm{b}]} / \mathrm{GM}$ & 310 & 510 & 410 & 510 \\
\hline$\lambda_{1-5^{[c]}} / \mathrm{nm}$ & 525 & 525 & 519 & 521 \\
\hline$\sigma_{1-5}\left[\mathrm{cc} / \mathrm{cm}^{2}\right.$ & $8.1 \times 10^{-17}$ & $9.5 \times 10^{-17}$ & $4.5 \times 10^{-17}$ & $11 \times 10^{-17}$ \\
\hline$\tau_{\text {gain }} / \mathrm{ns}$ & 0.27 & 1.4 & 1.1 & 1.2 \\
\hline
\end{tabular}

[a] The value is reported at spectral maximum, $\lambda_{1 P A}$. [b] The value is reported based on the result of ND-2PA measurements. The ND-2PA cross section is converted to the degenerated two-photon cross section as $\delta_{\mathrm{ND}}=2 \delta_{\mathrm{D}}$. [c] The value is reported at spectral maximum, $525 \mathrm{~nm}$, corresponding to the $\mathrm{S}_{1}-\mathrm{S}_{5}$ transition. 
(0.24 in toluene, 0.29 in DCM) and identical luminescence lifetimes. In marked contrast, $\mathbf{1}[\mathrm{Br}]$ featuring a smaller counterion presents a completely different behaviour in the two solvents. Heptamethine 1[Br] shows the characteristics of a cyanine state in DCM and the ion pair is fully dissociated. Consequently, both absorption and emission spectra are identical to that of $\mathbf{1}\left[\mathbf{B}\left(\mathbf{C}_{6} \mathbf{F}_{5}\right)_{4}\right]$. On the contrary, in toluene, the broad absorption band indicates a loss of the cyanine character. The strong optical and structural similarities to the related push-pull chromophore, as previously demonstrated, indicates that an inseparable ion-pair is formed in a non-dissociating solvent. The bromide anion polarizes the conjugated skeleton and the charge is localized at one extremity (Figure 1). ${ }^{10}$ In other words, a push-pull structure with one electron-donating indole and one electro-withdrawing indolenium moieties is obtained for $1[\mathrm{Br}]$ in toluene. It is worth noting that, the emission of $\mathbf{1}[\mathrm{Br}]$ in toluene is very weak with a dramatic decrease of the fluorescence quantum yield (0.04) and luminescence lifetime (Table 1). Interestingly, the emission profile is not the mirror image of the absorption one, but is comparable to a cyanine emission as that of $\mathbf{1}\left[\mathbf{B}\left(\mathbf{C}_{6} \mathbf{F}_{5}\right)_{4}\right]$ (Figure 2). This indicates that in the excited state, $1[\mathrm{Br}]$ in toluene presents a cyanine-like structure, with however a reduced fluorescence lifetime, suggesting faster non-radiative deexcitation process in the associated ion-pair (vide infra).

To monitor the cyanine-to-dipole transition and the formation of the ion pairs, the absorption and emission spectroscopies of $1[\mathrm{Br}]$ were studied in mixtures of DCM and toluene (Figure 3). As the proportion of toluene increases, it can be noticed that the cyaninetype absorption band gradually reduced. This observation reveals a dynamic association equilibrium between the heptamethine and its counterion in solution. The gradually broadening of the absorption band is accompanied by the decrease of the fluorescence quantum yields which accounts that a combination of polymethine of cyanine and dipolar forms can be found in solution (Table 2). It is noteworthy that there are minor changes in emission maxima and full-width at half-maximum (FWHM), regardless the mixing ratio of $\mathrm{DCM}$ and toluene, and the excitation spectra are all superimposable to the corresponding absorption spectra. ${ }^{33}$ These observations again suggest that the observed emission can be attributed to cyanine-type excited state in $1[\mathrm{Br}]$. The roles of cyanine- and dipole-type electronic structures effect on the nonlinear two-photon absorption properties are studied

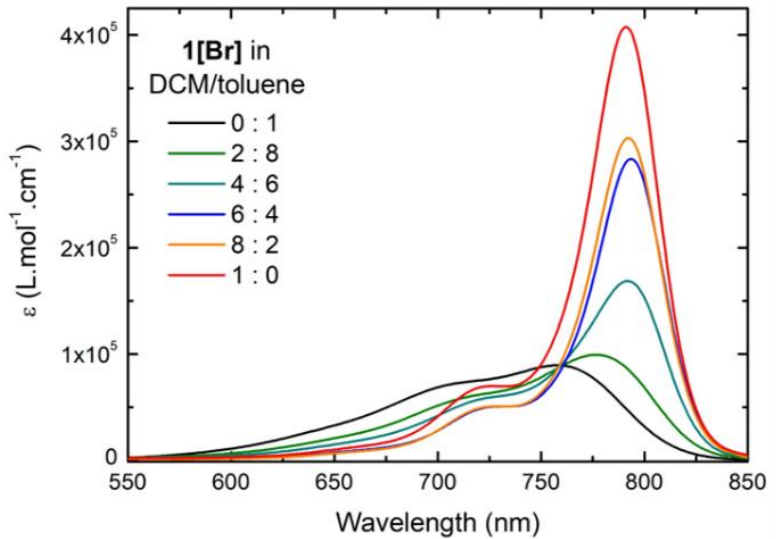

Table 2. Photophysical data for compound $1[\mathrm{Br}]$ in mixtures of DCM and toluene.

\begin{tabular}{ccccccc}
\hline $\begin{array}{c}\text { DCM : } \\
\text { toluene }\end{array}$ & $\begin{array}{c}\lambda_{\text {abs }} / \\
\mathrm{nm}\end{array}$ & $\begin{array}{c}\lambda_{\mathrm{em}} / \\
\mathrm{nm}\end{array}$ & $\Phi$ & $\tau / \mathrm{ns}$ & $\begin{array}{c}\mathrm{FWHM}^{\mathrm{abs}} / \\
\mathrm{cm}^{-1}\end{array}$ & $\begin{array}{c}\mathrm{FWHM}^{\mathrm{m}} / \\
\mathrm{Cm}^{-1}\end{array}$ \\
\hline $0: 1$ & 758 & 806 & 0.04 & $<0.4$ & 2337 & 834 \\
$2: 8$ & 777 & 811 & 0.04 & 0.5 & 1956 & 656 \\
$4: 6$ & 792 & 811 & 0.08 & 1.1 & 910 & 650 \\
$6: 4$ & 794 & 811 & 0.16 & 1.3 & 655 & 607 \\
$8: 2$ & 792 & 810 & 0.17 & 1.2 & 657 & 623 \\
$1: 0$ & 791 & 808 & 0.29 & 1.3 & 658 & 572 \\
\hline
\end{tabular}

using non-degenerate two-photon absorption spectroscopy (ND2PA) and open-aperture $z$-scan to characterize the 2PA spectra and the magnitude of 2PA cross sections, respectively.

The 2PA and excited state absorption (ESA) spectra of heptamethines $\mathbf{1}\left[\mathrm{Br}_{4}\right]$ and $\mathbf{1}\left[\mathbf{B}\left(\mathbf{C}_{6} \mathbf{F}_{5}\right)_{4}\right]$ in $\mathrm{DCM}$ and toluene are shown in Figure 4 and the corresponding optical parameters are listed in Table 1. As previously indicated in Figure 2, both heptamethines in DCM exhibit cyanine-type ground state electronic structure. According to the selection rule, the lowestenergy ground state transition of a polymethine is two-photon forbidden due to the symmetry. Both heptamethines show blueshifted 2PA maxima, in relative to the linear absorption maxima that overlap with the vibronic side band near $720 \mathrm{~nm}$ with sizable cross sections about $500 \mathrm{GM}$. This behaviour is assigned to the vibronic-allowed 2PA of the heptamethine. ${ }^{15}$ These measurements confirmed that the nature of the counter-ion has minor impact on the 2PA properties in a dissociating solvent like DCM. In toluene, $\mathbf{1}\left[\mathbf{B}\left(\mathbf{C}_{6} \mathbf{F}_{5}\right)_{4}\right]$ bearing the bulky anion shows the signature of vibronic-allowed 2PA near $720 \mathrm{~nm}$ with slightly reduced cross section of $\sim 400 \mathrm{GM}$. In contrast, $1[\mathrm{Br}]$ in toluene shows broaden, blue-shifted 2PA spectrum $(\sim 700 \mathrm{~nm})$ that overlaps the 1PA spectrum with a further reduced 2PA cross section of $\sim 300 \mathrm{GM}$ (Figure 5). The observed result again supports the previous discussion concerning the ground state electronic symmetry breaking due to ion-pairing effect and confirms that $\mathbf{1}[\mathrm{Br}]$ exhibits predominately a non-centrosymmetric dipolar electronic structure in nonpolar solvent.

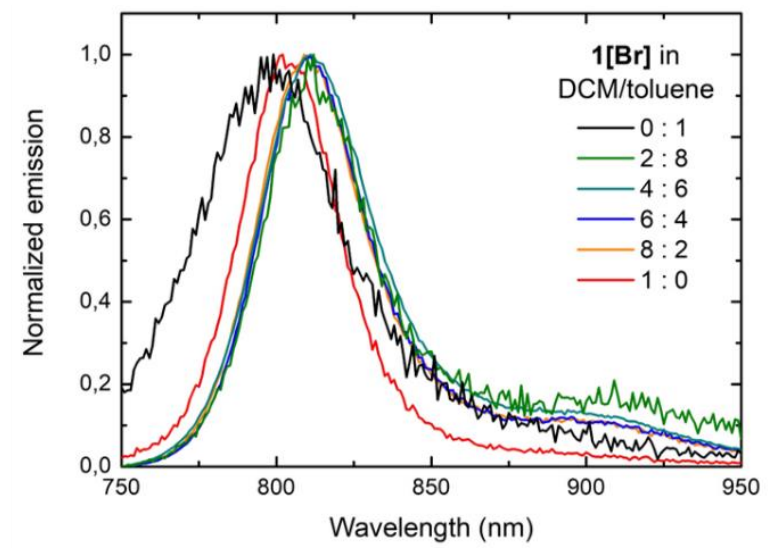

Figure 3. Absorption (left) and normalized emission (right) spectra recorded for $1[\mathrm{Br}]$ in mixtures of DCM and toluene. 

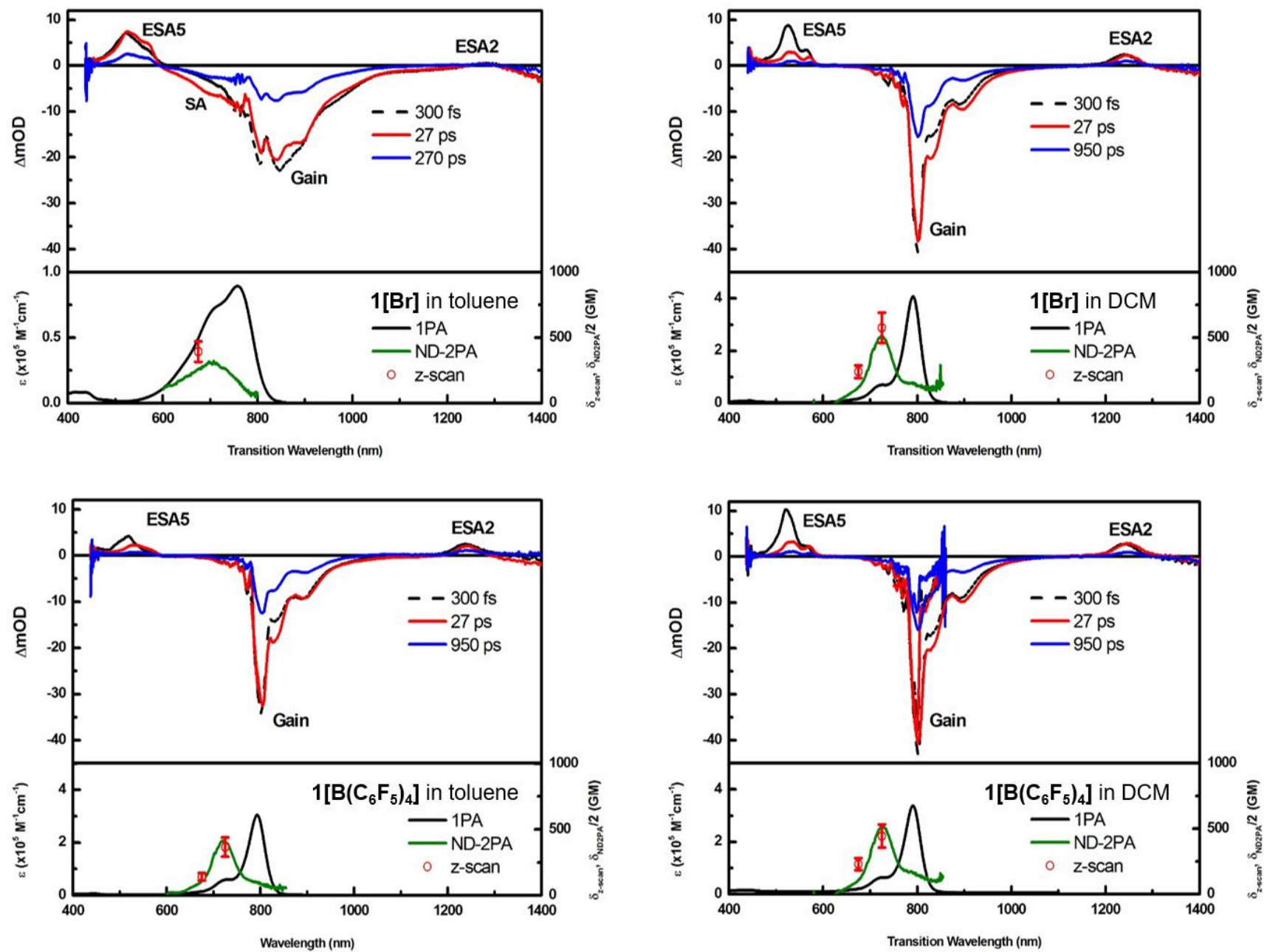

Figure 4. Linear, two-photon absorption, and transient absorption spectra of $\mathbf{1}[\mathrm{Br}]$ and $\mathbf{1}\left[\mathbf{B}\left(\mathbf{C}_{6} \mathbf{F}_{5}\right)_{4}\right]$ in toluene and $\mathrm{DCM}$.

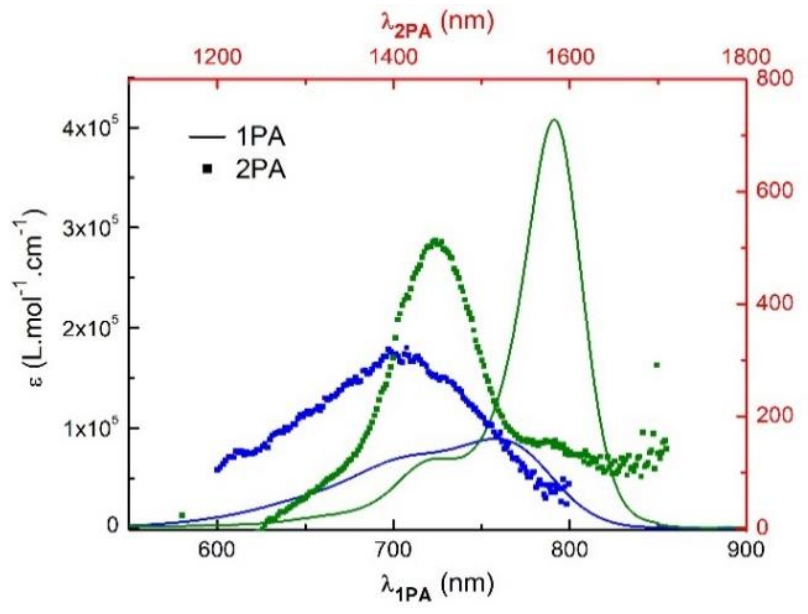

Figure 5. Linear (plain line) and two-photon (squares) absorptions of compounds $\mathbf{1}[\mathrm{Br}]$ (blue) and $\mathbf{1}\left[\mathbf{B}\left(\mathbf{C}_{6} \mathbf{F}_{5}\right)_{4}\right]$ (green) in toluene solution.

Ultrafast transient absorption spectroscopy was applied to observe the photophysics and establish structure-property relationships (Figures 4 and 6 ). In all cases, the stimulated emission (gain) is observed ca. $800 \mathrm{~nm}$, accompanied with two ESA bands $S_{1}-S_{5}$ at $525 \mathrm{~nm}$ and $S_{1}-S_{2}$ in the NIR. The stimulated emission confirms the fluorescence study, i.e. $1[\mathrm{Br}]$ in DCM and $\mathbf{1}\left[\mathbf{B}\left(\mathbf{C}_{6} \mathbf{F}_{5}\right)_{4}\right]$ in both $\mathrm{DCM}$ and toluene show intense and narrow gain at $800 \mathrm{~nm}$ with lifetime $\sim 1.1-1.4 \mathrm{~ns}$, similar to literature reported value. ${ }^{26,34}$ In addition, the symmetry breaking of $\mathbf{1}[\mathrm{Br}]$ in

toluene is also observed and leads to reduced gain intensity and lifetime (270 ps). One can notice that the profile of the stimulated emission presents a broad and structure-less transition, with redshifted peak ca. $840 \mathrm{~nm}$.

The cross section of ESA was extracted by a numerical method of nonlinear beam propagation. ${ }^{35}$ Concerning the NIR $S_{1}-S_{2}$ band, a slight difference can be observed in the case of $1[\mathrm{Br}]$ in toluene, but the signal is too weak to make any comment. The $S_{1}-S_{5}$ transition $\left(\lambda_{1-5}\right)$ around $525 \mathrm{~nm}$ is more intense with cross section $\left(\sigma_{1-5}\right)$ on the order of $1 \times 10^{-16} \mathrm{~cm}^{2}$, similar to the literature reported value. ${ }^{26,34}$ The size of cross sections $S_{1}-S_{5}$ of both $1[\mathrm{Br}]$ and $\mathbf{1}\left[\mathbf{B}\left(\mathbf{C}_{6} \mathbf{F}_{5}\right)_{4}\right]$ in toluene are relatively smaller compared to that in DCM. The kinetic of the $S_{1}-S_{5}$ (Figure 6) confirms the lifetime tendency previously discussed. It should be noted that the fast spike observed in the kinetic curve is due to the fast population of the excited state populations (depopulation of the ground state populations) stimulated by a white light continuum probe. 

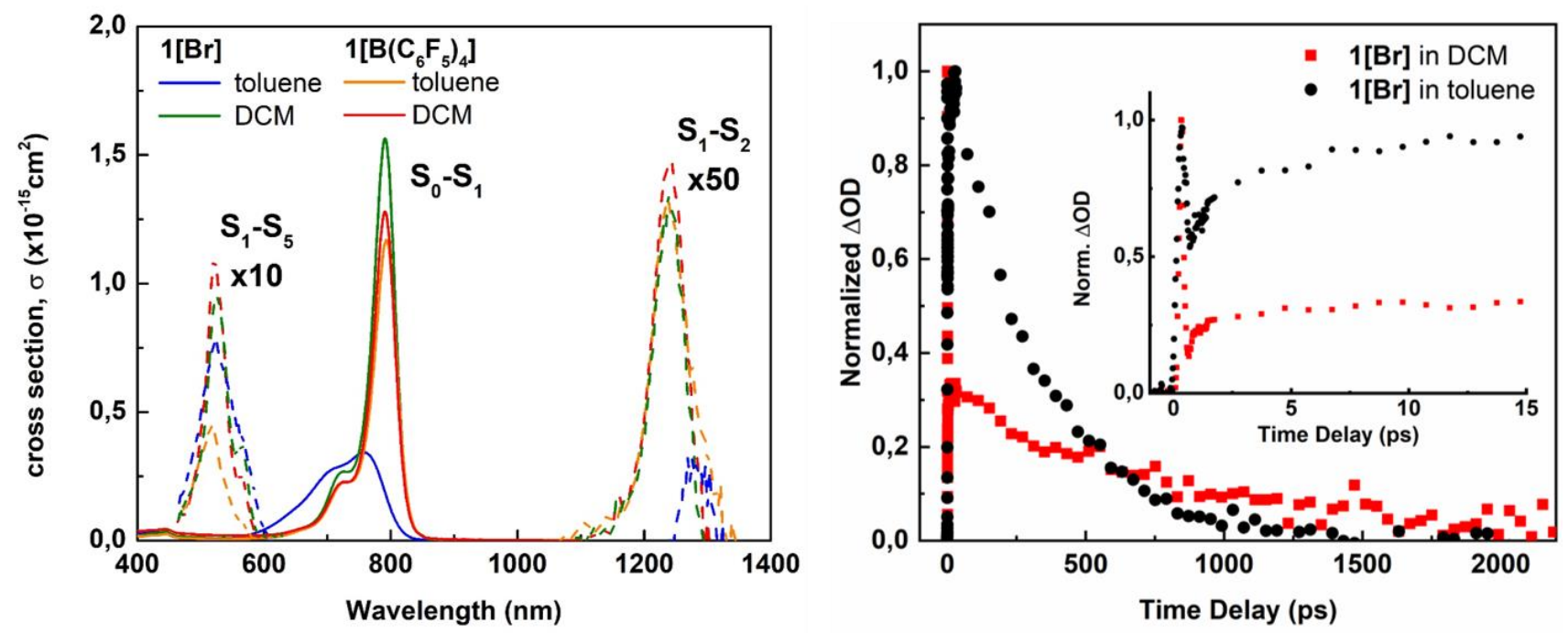

Figure 6. (Left) Linear (plain lines) and excited state absorption (dashed lines) cross sections of heptamethines $\mathbf{1}[\mathrm{Br}]$ and $\mathbf{1}\left[\mathbf{B}\left(\mathrm{C}_{6} \mathrm{~F}_{5}\right)_{4}\right]$. (Right) Kinetics of $\mathrm{S}_{1}-\mathrm{S}_{5}$ transition of $\mathbf{1}[\mathrm{Br}]$ in DCM and toluene.

\section{Conclusion}

In conclusion, we studied the cyanine-to-dipole transition in heptamethine dyes using emission, nonlinear and transient absorption spectroscopies. The investigation of the fluorescence pointed out that both electronic structures give rise to an emission from a cyanine-type excited state. Moreover, the progressive transition between the dipolar and cyanine forms revealed a dynamic association equilibrium between the heptamethine and its counterion in solution. The establishment of a polyene-like electronic structure could be monitored for the first time with nonlinear absorption measurements, highlighting the overlap of the 1PA and 2PA transitions in the dipolar state in the NIR, due to the ground state symmetry breaking induced by ion-pairing.

\section{Experimental Section}

Synthetic procedures. The synthesis of heptamethine 1 was performed following a reported procedure. ${ }^{36}$ NMR spectra were recorded at room temperature on a BRUKER $^{\circledR}$ Avance operating at $500.1 \mathrm{MHz}, 125.8 \mathrm{MHz}$ and $188.8 \mathrm{MHz}$ for ${ }^{1} \mathrm{H},{ }^{13} \mathrm{C}$ and ${ }^{19} \mathrm{~F}$, respectively. ${ }^{13} \mathrm{C}$ NMR signals were assigned using HSQC and HMBC experiments. Chemical shifts are listed in parts per million $(\delta, \mathrm{ppm})$ and are reported relative to residual solvent peaks being used as internal standard (for ${ }^{1} \mathrm{H}$ and ${ }^{13} \mathrm{C}$ respectively: $\mathrm{CDCl}_{3}: 7.26$ and $77.2 \mathrm{ppm}$ ). Hydrogen atoms in equatorial or axial configuration are noted $\mathrm{H}_{\text {eq }}$ or $\mathrm{H}_{\mathrm{ax}}$, respectively. High resolution mass spectrometry measurements were performed at the Centre Commun de Spectrometrie de Masse (Villeurbanne, France).
Synthesis of compound $1\left[\mathbf{B}\left(\mathbf{C}_{6} \mathbf{F}_{5}\right)_{4}\right]$ : a Schlenk tube was charged with $50 \mathrm{mg}$ of heptamethine $1[\mathrm{Br}](0.05 \mathrm{mmol}$, 1 equiv), $47 \quad \mathrm{mg}$ of lithium tetrakis(pentafluorophenyl)borate ethyletherate $(0.05$ mmol, 1 equiv) and added by $10 \mathrm{~mL}$ of anhydrous dichloromethane. The solution was stirred for 30 minutes at $25^{\circ} \mathrm{C}$, then washed with water $(2 \times 10 \mathrm{~mL})$, dried over anhydrous $\mathrm{Na}_{2} \mathrm{SO}_{4}$ and concentrated under reduced pressure. After filtration trough a silicagel plug with dichloromethane, the product was isolated as a green solid in a $98 \%$ yield $(80 \mathrm{mg}) .{ }^{1} \mathrm{H} \mathrm{NMR}\left(\mathrm{CDCl}_{3}, 500\right.$ $\mathrm{MHz}): \delta=8.39\left(\mathrm{~d},{ }^{3} \mathrm{~J}=14 \mathrm{~Hz}, 2 \mathrm{H},=\mathrm{CH}\right), 7.36\left(\mathrm{~d},{ }^{3} \mathrm{~J}=8\right.$ $\left.\mathrm{Hz}, 4 \mathrm{H}, \mathrm{CH}_{\mathrm{Ar}}\right), 7.25\left(\mathrm{~d},{ }^{3} \mathrm{~J}=8 \mathrm{~Hz}, 2 \mathrm{H}, \mathrm{CH}_{\mathrm{Ar}}\right), 7.06\left(\mathrm{~d},{ }^{3} \mathrm{~J}\right.$ $\left.=8 \mathrm{~Hz}, 2 \mathrm{H}, \mathrm{CH}_{\mathrm{Ar}}\right), 6.05\left(\mathrm{~d},{ }^{3} \mathrm{~J}=14 \mathrm{~Hz}, 2 \mathrm{H},=\mathrm{CH}\right), 3.97$ $\left(\mathrm{t},{ }^{3} \mathrm{~J}=7 \mathrm{~Hz}, 4 \mathrm{H}, \mathrm{N}-\mathrm{CH}_{2}\right.$ ), $2.84\left(\mathrm{dd},{ }^{2} \mathrm{~J}=14 \mathrm{~Hz},{ }^{3} \mathrm{~J}=3\right.$ $\mathrm{Hz}, 2 \mathrm{H}, \mathrm{H}_{\mathrm{eq}}$ ), 2.19 (dd, ${ }^{2} \mathrm{~J}=14 \mathrm{~Hz},{ }^{3} \mathrm{~J}=14 \mathrm{~Hz}, 2 \mathrm{H}, \mathrm{H}_{\mathrm{ax}}$ ), 1.82 (quint, $\left.{ }^{3} \mathrm{~J}=7 \mathrm{~Hz}, 4 \mathrm{H}, \mathrm{CH}_{2}\right), 1.70\left(\mathrm{~s}, 6 \mathrm{H}, \mathrm{C}\left(\mathrm{CH}_{3}\right)_{2}\right)$, $1.69\left(\mathrm{~s}, 6 \mathrm{H}, \mathrm{C}\left(\mathrm{CH}_{3}\right)_{2}\right), 1.60(\mathrm{~m}, 1 \mathrm{H}, \mathrm{CH}), 1.44-1.33(\mathrm{~m}$, $\left.8 \mathrm{H}, \mathrm{CH}_{2}\right), 1.23\left(\mathrm{~m}, 28 \mathrm{H}, \mathrm{CH}_{2}\right), 1.04\left(\mathrm{~s}, 9 \mathrm{H}, \mathrm{C}\left(\mathrm{CH}_{3}\right)_{3}\right)$, $0.87\left(\mathrm{t},{ }^{3} \mathrm{~J}=7 \mathrm{~Hz}, 6 \mathrm{H}, \mathrm{CH}_{3}\right) .{ }^{13} \mathrm{C} \mathrm{NMR}\left(\mathrm{CDCl}_{3}, 126 \mathrm{MHz}\right)$ : $\delta=172.9(\mathrm{C}), 151.5(\mathrm{C}), 149.3(\mathrm{~m}, \mathrm{C}), 147.3(\mathrm{~m}, \mathrm{C})$, $145.0(\mathrm{CH}), 142.0(\mathrm{C}), 141.2(\mathrm{C}), 137.3(\mathrm{~m}, \mathrm{C}), 135.5$ $(\mathrm{m}, \mathrm{C}), 129.0(\mathrm{CH}), 127.2(\mathrm{C}), 125.8(\mathrm{CH}), 122.6(\mathrm{CH})$, $110.7(\mathrm{CH}), 100.5(\mathrm{CH}), 49.6(\mathrm{C}), 44.6\left(\mathrm{NCH}_{2}\right), 42.3$ (CH), $32.4(\mathrm{C}), 32.1\left(\mathrm{CH}_{2}\right), 29.7\left(2 \mathrm{CH}_{2}\right.$ or $\left.2 \mathrm{CH}_{3}\right), 29.6$ $\left(\mathrm{CH}_{2}\right.$ or $\left.\mathrm{CH}_{3}\right), 29.6\left(\mathrm{CH}_{2}\right.$ or $\left.\mathrm{CH}_{3}\right), 29.4\left(\mathrm{CH}_{2}\right.$ or $\left.\mathrm{CH}_{3}\right), 29.3$ $\left(\mathrm{CH}_{2}\right.$ or $\left.\mathrm{CH}_{3}\right), 28.2\left(\mathrm{CH}_{2}\right.$ or $\left.\mathrm{CH}_{3}\right), 28.1\left(\mathrm{CH}_{2}\right.$ or $\left.\mathrm{CH}_{3}\right), 27.4$ $\left(2 \mathrm{CH}_{2}\right.$ or $\left.2 \mathrm{CH}_{3}\right), 27.2\left(\mathrm{CH}_{2}\right.$ or $\left.\mathrm{CH}_{3}\right), 22.8\left(\mathrm{CH}_{2}\right), 14.2$ $\left(\mathrm{CH}_{3}\right) \cdot{ }^{19} \mathrm{~F} \mathrm{NMR}\left(\mathrm{CDCl}_{3}, 189 \mathrm{MHz}\right): \delta=-132.5\left(\mathrm{~d}, J_{F-F}=\right.$ $11 \mathrm{~Hz}, 2 \mathrm{~F}),-163.3$ (t, $\left.J_{F-F}=20 \mathrm{~Hz}, 1 \mathrm{~F}\right),-166.9$ (t, $J_{F-F}=$ $18 \mathrm{~Hz}, 2 \mathrm{~F})$. UV-Vis $\left(\mathrm{CH}_{2} \mathrm{Cl}_{2}\right): \lambda_{\max }=791 \mathrm{~nm}\left(\varepsilon_{\max }=\right.$ 338000 L. $\left.\mathrm{mol}^{-1} . \mathrm{cm}^{-1}\right)$. HRMS (ESI+): $[\mathrm{M}]^{+}=847.6596$ (calculated for $\mathrm{C}_{58} \mathrm{H}_{88} \mathrm{CIN}_{2}$ : 847.6631).

Linear absorption and luminescence. Absorption spectra were recorded on a JASCO V-650 spectrophotometer in diluted solution (ca. $10^{-6} \mathrm{~mol}^{-\mathrm{L}^{-1}}$ ) using spectrophotometric grade solvents. Molar extinction coefficients $(\varepsilon)$ were precisely determined at 
least two times. Emission spectra were measured using a Horiba-Jobin-Yvon Fluorolog-3 iHR320 fluorimeter. Fluorescence quantum yields $Q$ were measured in diluted solutions with an absorbance lower than 0.1 using the following equation $Q_{x} / Q_{\mathrm{r}}=$ $\left[A_{r}(\lambda) / A_{x}(\lambda)\right]\left[\mathrm{n}_{x}^{2} / \mathrm{n}_{\mathrm{r}}^{2}\right]\left[D_{\mathrm{x}} / D_{\mathrm{r}}\right]$ were $A$ is the absorbance at the excitation wavelength $(\lambda), \mathrm{n}$ the refractive index and $D$ the integrated luminescence intensity. " $r$ " and " $x$ " stand for reference and sample. The fluorescence quantum yields were measured relative to IR-125 in DMSO $(\Phi=0.13)$. Excitation of reference and sample compounds was performed at the same wavelength. Short luminescence decay was monitored with the TCSPC Horiba apparatus using Ludox in distilled water to determine the instrumental response function used for deconvolution. Excitation was performed using NanoLEDs, with model 740 (732 nm; $1.3 \mathrm{~ns})$. The deconvolution was performed using the DAS6 fluorescence-decay analysis software.

Two-photon and transient absorptions. All solutions were prepared in spectroscopic grade DCM (Acros Organics) with the averaged concentration of $\sim 0.5-1.5$ $\mathrm{mM}$ for ND-2PA and z-scan measurements and $\sim 10$ $100 \mu \mathrm{M}$, to obtain optical densities between 0.6-1, for transient absorption (TA) spectroscopy. All samples were stirred continuously during measurements in $2 \mathrm{~mm}$ path-length fused silica cuvettes. The two-photon absorption (2PA) spectra were mapped with femtosecond-pulsed ND-2PA spectrometer ${ }^{34}$ and the 2PA absorption cross sections, $\delta$ in $\mathrm{GM}$, were confirmed with femtosecond-pulsed open aperture z-scan techniques. For ND-2PA measurements, excitation wavelengths of 1800 and a white light continuum (WLC) probe ranging from 950-1600 $\mathrm{nm}$ were selected to acquire the ND-2PA spectra from transition wavelength of $620-850 \mathrm{~nm}$. For z-scan measurements, a near Gaussian beam at 1450 and $1350 \mathrm{~nm}$ with $\mathrm{M}^{2}<1.1$, $\omega\left(\mathrm{HW}_{1 / \mathrm{e} 2}\right) \sim 50 \mu \mathrm{m}$, and $\tau \mathrm{p}\left(\mathrm{HW}_{1 / \mathrm{e}}\right) \sim 75 \mathrm{fs}$ was used. The excitation irradiance ranges from $30-120 \mathrm{GW} / \mathrm{cm}^{2}$. By definition, the ND-2PA measured two-photon cross section $\left(\delta_{N D}\right)$ should be 2 times larger than the z-scan measured degenerated two-photon cross section $\left(\delta_{D}\right)$. Femtosecond TA spectra and kinetic traces were measured with a commercially available broadband pump-probe spectrometer (HELIOS, Ultrafast Systems LLC) using a femtosecond Ti:Sapphire regenerative amplifier laser source (Solstice, Spectra-Physics, 800$\mathrm{nm}, 3.7-\mathrm{W}$ average power, 100-fs pulse width, $1-\mathrm{KHz}$ repetition rate) and a computer-controlled optical parametric amplifier (OPA) (TOPAS, Spectra-Physics, wavelength range: $266-2290 \mathrm{~nm}$, pulse width: $\sim 75$ fs HW1/e) pumped by the amplified laser. The excitation wavelength of $780 \mathrm{~nm}$ was generated using the output of OPA. The white-light continuum (WLC, 400-1600 nm) probe beam was produced by focusing less than $5 \%$ of the $800 \mathrm{~nm}$ amplified beam into a nonlinear crystal in the Helios. A chirp correction function for the WLC probe was determined using measurements of the nondegenerate nonlinear response of tetrahydrofuran and was applied to all transient spectra. ${ }^{37}$
Keywords: cyanine $\cdot$ polymethine $\cdot$ two-photon

absorption $\cdot$ spectroscopy $\bullet$ near-infrared dyes

[1] A. Mishra, R. K. Behera, P. K. Behera, B. K. Mishra, G. B. Behera Chem. Rev. 2000, 100, 1973-2012.

[2] A. V. Kulinich, A. I. Aleksandr Russ. Chem. Rev. 2009, 78, 141.

[3] J. L. Bricks, A. D. Kachkovskii, Y. L. Slominskii, A. O. Gerasov, S. V. Popov Dyes Pigm. 2015, 121, 238-255.

[4] K. Kiyose, H. Kojima, T. Nagano Chem. Asian J. 2008, 3, 506-515.

[5] G. Qian, Z. Y. Wang Chem. Asian J. 2010, 5, 1006-1029.

[6] Z. Guo, S. Park, J. Yoon, I. Shin Chem. Soc. Rev. 2014, 43, 16-29.

[7] P.-A. Bouit, D. Rauh, S. Neugebauer, J. L. Delgado, E. D. Piazza, S. p. Rigaut, O. Maury, C. Andraud, V. Dyakonov, N. Martin Org. Lett. 2009, 11, 4806-4809.

[8] A. Pertegás, D. Tordera, J. J. Serrano-Pérez, E. Ortí, H. J. Bolink J. Am. Chem. Soc. 2013, 135, 18008-18011.

[9] S. Seo, S. Pascal, C. Park, K. Shin, X. Yang, O. Maury, B. D. Sarwade, C. Andraud, E. Kim Chem. Sci. 2014, 5, 15381544.

[10] P.-A. Bouit, C. Aronica, L. Toupet, B. Le Guennic, C. Andraud, O. Maury J. Am. Chem. Soc. 2010, 132, 43284335.

[11] W. Sun, S. Guo, C. Hu, J. Fan, X. Peng Chem. Rev. 2016, 116, 7768-7817.

[12] T.-C. Wang, F. Cochet, F. A. Facchini, L. Zaffaroni, C. Serba, S. Pascal, C. Andraud, A. Sala, F. Di Lorenzo, O. Maury, T. Huser, F. Peri Bioconjugate Chem. 2019, 30, 1649-1657.

[13] P.-A. Bouit, G. Wetzel, G. Berginc, B. Loiseaux, L. Toupet, P. Feneyrou, Y. Bretonnière, K. Kamada, O. Maury, C. Andraud Chem. Mater. 2007, 19, 5325-5335.

[14] J. M. Hales, J. Matichak, S. Barlow, S. Ohira, K. Yesudas, J.L. Brédas, J. W. Perry, S. R. Marder Science. 2010, 327, 1485-1488.

[15] Q. Bellier, N. S. Makarov, P.-A. Bouit, S. Rigaut, K. Kamada, P. Feneyrou, G. Berginc, O. Maury, J. W. Perry, C. Andraud Phys. Chem. Chem. Phys. 2012, 14, 15299-15307.

[16] J. M. Hales, S. Barlow, H. Kim, S. Mukhopadhyay, J.-L. Brédas, J. W. Perry, S. R. Marder Chem. Mater. 2013, 26 , 549-560.

[17] S. Barlow, J.-L. Bredas, Y. A. Getmanenko, R. L. Gieseking, J. M. Hales, H. Kim, S. R. Marder, J. W. Perry, C. Risko, Y. Zhang Mater. Horiz. 2014, 1, 577-581.

[18] W. Bentoumi, J.-C. Mulatier, P.-A. Bouit, O. Maury, A. Barsella, J.-P. Vola, E. Chastaing, L. Divay, F. Soyer, P. Le Barny, Y. Bretonnière, C. Andraud Chem. Eur. J. 2014, 20, 8909-8913.

[19] S. Pascal, Y. A. Getmanenko, Y. Zhang, I. Davydenko, M. H. Ngo, G. Pilet, S. Redon, Y. Bretonnière, O. Maury, I. LedouxRak, S. Barlow, S. R. Marder, C. Andraud Chem. Mater. 2018, 30, 3410-3418.

[20] S. Mukhopadhyay, C. Risko, S. R. Marder, J.-L. Bredas Chem. Sci. 2012, 3, 3103-3112.

[21] A. C. Véron, H. Zhang, A. Linden, F. Nüesch, J. Heier, R. Hany, T. Geiger Org. Lett. 2014, 16, 1044-1047.

[22] R. L. Gieseking, S. Mukhopadhyay, C. Risko, S. R. Marder, J.-L. Brédas Adv. Mater. 2014, 26, 68-84.

[23] S. Pascal, A. Haefele, C. Monnereau, A. Charaf-Eddin, D. Jacquemin, B. Le Guennic, O. Maury, C. Andraud Proc. SPIE. 2014, 9253A, 1-11.

[24] L. G. S. Brooker, R. H. Sprague, C. P. Smyth, G. L. Lewis J. Am. Chem. Soc. 1940, 62, 1116-1125.

[25] L. M. Tolbert, X. Zhao J. Am. Chem. Soc. 1997, 119, 32533258.

[26] R. S. Lepkowicz, O. V. Przhonska, J. M. Hales, J. Fu, D. J. Hagan, E. W. Van Stryland, M. V. Bondar, Y. L. Slominsky, A. D. Kachkovski Chem. Phys. 2004, 305, 259-270. 
[27] F. Würthner, R. Wortmann, R. Matschiner, K. Lukaszuk, K. Meerholz, Y. De Nardin, R. Bittner, C. Bräuchle, R. Sens Angew. Chem. Int. Ed. 1997, 36, 2765-2768.

[28] F. Würthner, G. Archetti, R. Schmidt, H.-G. Kuball Angew. Chem. Int. Ed. 2008, 47, 4529-4532.

[29] S. Pascal, P.-A. Bouit, B. Le Guennic, S. Parola, O. Maury, C. Andraud Proc. SPIE. 2013, 86220F, 1-9.

[30] S. Pascal, A. Haefele, C. Monnereau, A. Charaf-Eddin, D. Jacquemin, B. Le Guennic, C. Andraud, O. Maury J. Phys. Chem. A. 2014, 118, 4038-4047.

[31] Y. Kada J. Mol. Struct. 2019, 1186, 127-136.

[32] M. Eskandari, J. C. Roldao, J. Cerezo, B. Milián-Medina, J. Gierschner J. Am. Chem. Soc. 2020, 142, 2835-2843.

[33] A. A. Ishchenko Russ. Chem. Rev. 1991, 60, 865-884.

[34] R. A. Negres, O. V. Przhonska, D. J. Hagan, E. W. Van Stryland, M. V. Bondar, Y. L. Slominsky, A. D. Kachkovski Selected Topics in Quantum Electronics, IEEE Journal of. 2001, 7, 849-863.

[35] S.-H. Chi, J. M. Hales, M. Cozzuol, C. Ochoa, M. Fitzpatrick, J. W. Perry Opt. Express. 2009, 17, 22062-22072.

[36] S. Pascal, S. Denis-Quanquin, F. Appaix, A. Duperray, A. Grichine, B. Le Guennic, D. Jacquemin, J. Cuny, S.-H. Chi, J. W. Perry, B. van der Sanden, C. Monnereau, C. Andraud, O. Maury Chem. Sci. 2017, 8, 381-394.

[37] S. A. Kovalenko, A. L. Dobryakov, J. Ruthmann, N. P. Ernsting, Phys. Rev. A 1999, 59, 2369-2384. 